Short Communication

\title{
Effect of $\beta$-cyclodextrin as Organic Additive on Pulse Electrodeposition of Nanocrystalline Ni-W Coating
}

Qiangbin Yang ${ }^{1,2,3}, \mathrm{Yi} \mathrm{He}^{1, *}$, Yi Fan ${ }^{1,2,3}$, Yingqing Zhan ${ }^{2,3, *}$, Ying Tang ${ }^{2,3}$

${ }^{1}$ State Key Lab of Oil and Gas Reservoir Geology and Exploitation (Southwest Petroleum University), Chengdu 610500, P. R. China

${ }^{2}$ Oil \& Gas Field Applied Chemistry Key Laboratory of Sichuan Province (Southwest Petroleum University), Chengdu 610500, P. R. China

${ }^{3}$ School of Chemistry and Chemical Engineering, Southwest Petroleum University, Chengdu 610500, P. R. China

*E-mail: heyi007@163.com, 327814719@qq.com

doi: $10.20964 / 2016.06 .89$

Received: 28 November 2015 / Accepted: 21 January 2016 / Published: 4 May 2016

Nanocrystalline nickel-tungsten (Ni-W) coatings was obtained by pulse electrodeposition in the plating bath with and without containing $\beta$-cyclodextrin $(\beta$-CD). The mirco-structure and morphologies of coatings were characterized by energy dispersive spectrometer (EDS), X-ray diffraction (XRD) and scanning electron microscopy (SEM). It was found that smaller grain size and more compact surface structure can be realized by introduction of $\beta-\mathrm{CD}$, which had no influence on the compositions of the coating. More importantly, the coating had better anticorrosion and mechanical performance.

Keywords: $\beta$-cyclodextrin; Ni-W; nanocrystalline materials; corrosion; pulse electrodeposition.

\section{FULL TEXT}

(C) 2016 The Authors. Published by ESG (www.electrochemsci.org). This article is an open access article distributed under the terms and conditions of the Creative Commons Attribution license (http://creativecommons.org/licenses/by/4.0/). 